\title{
Magnetite Nanoparticle Green Synthesis from Canola Oil
}

\author{
ASHISH KUMAR \\ Chemical Laboratories, School of Civil Engineering, Lovely Professional University, Punjab, India. \\ ${ }^{*}$ Corresponding author E-mail: drashishchemlpu @ gmail.com \\ http://dx.doi.org/10.13005/ojc/300219
}

(Received: April 10, 2014; Accepted: May 19, 2014)

\begin{abstract}
Nanomagnetite can be synthesized in lab by decomposition method using $\mathrm{FeOOH}$ and oleic acid in 1-ODEbut the cost of production is very high. Here we are trying to synthesize cost effective nanomagnetites by using common materials present in our daily life which are freely available in market .Magnetite nanocrystals are highly useful in arsenic remediation as arsenic contamination in groundwater is a severe global problem. In India, millions suffer from acute and chronic arsenic poisoning. It is possible to create functional and high-quality nanocrystals using this greener and cost effective method.Our research revealed that the costs of the starting materials can be reduced by using this greener synthetic route
\end{abstract}

Key words: Nanomagnetite, contamination, Arsenic remediation, Drinking water, green synthetic, Magnetite nanocrystals.

\section{INTRODUCTION}

\section{Aims and Background}

Physical substances with at least one characteristic dimension between 1-150 nm can be defined as nanomaterials. Nanomaterials properties can differ from those of the same materials with micron- or $\mathrm{mm}$-scale dimensions. Nanomaterials are the building blocks of practical nanotechnology and can be physically and chemically manipulated for specific application. Nanotechnology has been proved efficient in improving air, water, and soil quality in the environment. It can progress detection and sensing of pollutants and help in the development of other new technologies for control. The synthesis of fine sizes of magnetite usually require highly pure chemicals and laboratory tools, such as temperature-controlled heaters, stirrers, and inert atmosphere. Non-aqueous mediums are also preferred for high monodispersity and uniformity ${ }^{[1]}$ In a typical synthesis, an iron salt or oxide is mixed with a surfactant and boiled in a high boiling point solvent under air-free reflux conditions. The most notable examples of this type of synthesis are refluxing iron acetylacetonate, oleic acid, oleylamine and 1,2-hexadecanediol in diphenyl ether ${ }^{2,3}$, heating iron oxohydrate $(\mathrm{FeOOH})$ with oleic acid in 1-octadecene $(\mathrm{ODE})^{4}$, precipitating $\mathrm{FeCl}_{3}$ with oleic acid and further heating to a boiling in 1 
-octadecene $(\mathrm{ODE})^{5}$, and mixing $\mathrm{FeCl}_{3}$ and sodium oleate before refluxing the precipitate in a mixture of oleic acid and $\mathrm{ODE}^{6}$.

All of these methods, however, require high purity grade chemicals, thereby limiting their use in very low cost operations. So our aim is to synthesize magnetite nanoparticles for environment friendly uses through chemicals readily available in open market. Earlier soya bean, corn and olive oil were used to synthesize nanomaterials by kitchen synthesis ${ }^{[12]}$.

\section{EXPERIMENTAL}

\section{Materials}

Edible oil: Canadian pride Canola oil, Pidilite klog remover, Top's vinegar was purchased from market. Water was used from laboratory tap water without further purification. Rust was obtained from different sources of rusted iron, such as the iron sheet that was found inside university campus , iron angles and rods found in the playground of university(Fig.1-5)

\section{Soap making process}

Pidilite klog remover $(15 \mathrm{~g})$ is dissolved in $30 \mathrm{ml}$ of tap water and, while warm, poured into a glass bowl containing $100 \mathrm{~g}$ of canola oil. The mixture is stirred with a wooden spoon and kept in open area to dry and cure, until a thick, hard soap is obtained.(Fig.6)

\section{Production of fatty acid mixture}

The cured soap $(50 \mathrm{~g})$ is finely grated and mixed with $500 \mathrm{ml}$ of tops vinegar. The resulting solution is boiled for $15-30 \mathrm{~min}$, with stirring, until all soap gets dissolved. Upon cooling, two layers

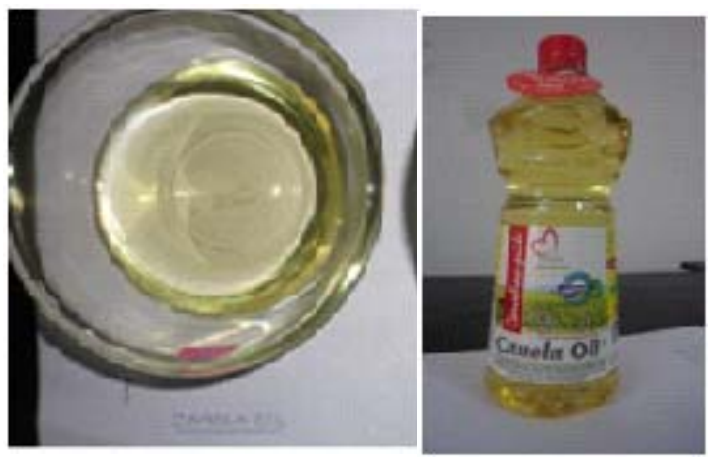

Fig. 1: Canola oil are formed. The top organic layer is removed and placed in a pan. This cloudy yellow mixture is heated to a boil until the remaining water and acetic acid evaporates.

\section{Magnetite nanocrystal synthesis}

Rust is obtained from rusted steel sources. Rust powder (2 $\mathrm{g}$ ) is mixed with $30 \mathrm{~g}$ fatty acid mixture (FAM) and placed into the pan. Covered by a lid, the solution is boiled for $2 \mathrm{hr}$, producing a thick smoke. This thick smoke diminishes in time, and the end product is a black gelatinous magnetic material (Fig.7).The soap $(5 \mathrm{~g})$ is dissolved into $50 \mathrm{ml}$ of hot water and boiled until dissolved. $5 \mathrm{~g}$ slurry from the pan is mixed with the soapy water and boiled for 30 $\mathrm{min}$. The unreacted solid is removed by filtering. Watersoluble magnetite nanocrystals are then magnetically collected. The deposits on the magnet are then washed with water and redispersed in water or ethanol.

\section{RESULTS AND DISCUSSION}

Limited greener and cost-effective synthetic methods are reported in the field of nanotechnology. The most common olive oil ${ }^{9}$ and Therminol $66^{10}$ have been shown to be directly usable as solvents.

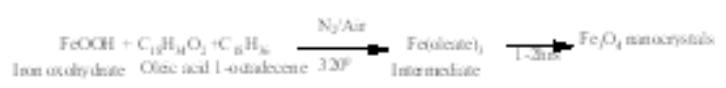

In this greener route, the main starting materials of the synthesis, iron precursor and the oleic acid, can be replaced with readily available chemicals. Edible oil such as canola oil can replace oleic acid with a mixture of fatty acids that are formed via saponification that is followed by acidification. Rust is the common replacement of $\mathrm{FeOOH}$,. The new chemical reaction ${ }^{12}$ then becomes:

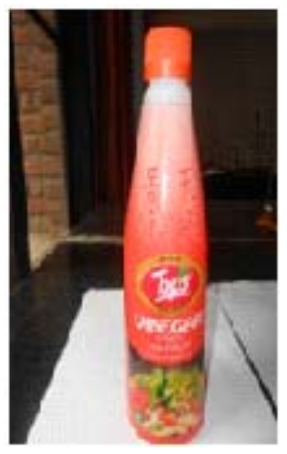

Fig. 2: Tops vinegar 
Rust (hydrated iron oxides) + Fatty Acid Mixture $(\mathrm{FAM})$ Magnetite $\left(\mathrm{Fe}_{3} \mathrm{O}_{4}\right) \longrightarrow$ Nanocrystals

Soap(mixture of fatty acid salts) is produced by saponification of canola oil , The FAM, which is a mixture of long-chain organic acids, forms once this soap is acidified with vinegar. There are different fatty acids that constitute FAMs, but four of these are almost always dominant ${ }^{13}$ : oleic acid [(9Z)-octadec-9-enoic acid], linoleic acid [(9Z, 12Z)octadeca-9, 12-dienoic acid], stearic acid (octadecanoic acid), and palmitic acid (hexadecanoic acid)

\section{IR Spectrum}

The peak at $570.95 \mathrm{~cm}^{-1}$ is assigned to the $\mathrm{Fe}-\mathrm{O}$ bond vibration of $\mathrm{Fe}_{3} \mathrm{O}_{4}$ nanoparticles

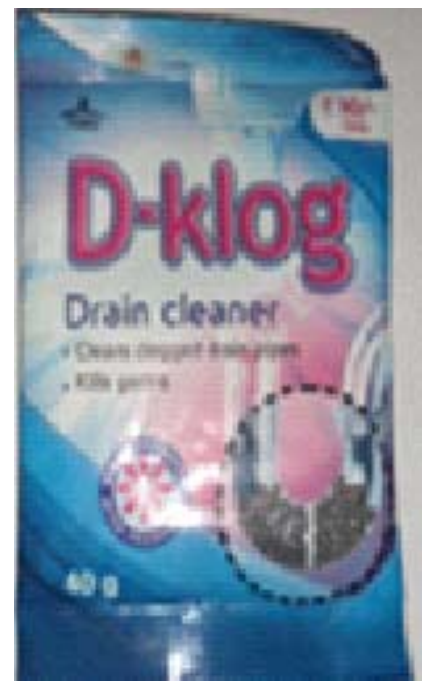

Fig. 3: Pedillite Clog remover

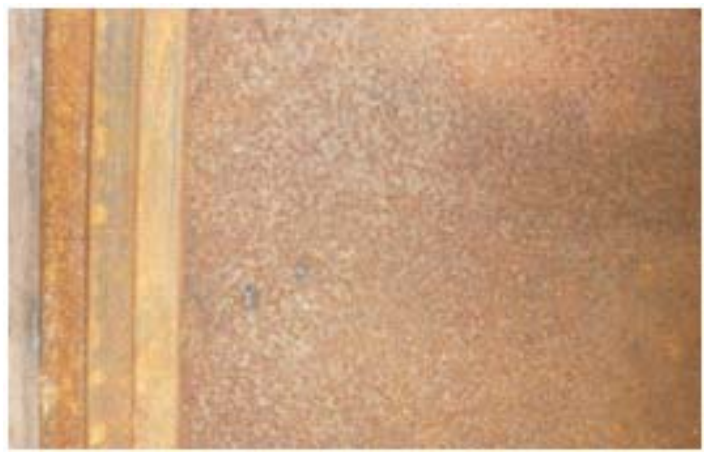

Fig. 4: View of Rusted iron sheet at 3 feet distance confirming the formation of nanomagnetites.

\section{TEM Analysis}

In order to determine the characteristics of magnetite nanoparticles, high resolution transmission electron microscopy (HRTEM) images were obtained at the main zone axes. Fig.9- HRTEM images

The $\mathrm{Fe}_{3} \mathrm{O}_{4}$ nanoparticles dispersed in ethanol were dropped on carbon film coated copper grids. The self-assembly formed as the hexane evaporated and its morphology and structure were investigated by means of transmission electron microscopy (TEM). The $\mathrm{Fe}_{3} \mathrm{O}_{4}$ nanoparticle solution was poured in a capsule and put in a Quantum Design SQUID (MPMS-5s) for magnetic characterization. STEM analysis of nanomagnetites prepared from canola oil show that general size is from 20-100 nm.

\section{Applications of Nanomagnetites}

1. Arsenic (As) in drinking water is an epidemic affecting millions of people living in Southeast Asia including India and Bangladesh [11]. The toxicity of arsenic to human health ranges from skin lesions to cancer of the brain, liver, kidney, and stomach Nanomagnetites were used as a most efficient agent for removal of heavy metals such as As and $\mathrm{Cr}$ for cleaning polluted water. Arsenic is naturally present in groundwater in the forms of arsenite $\left(\mathrm{AsO}_{3}{ }^{3}\right)$ and arsenate $\left(\mathrm{AsO}_{4}{ }^{3-}\right)$. These anions resemble phosphite $\left(\mathrm{HPO}_{3}^{2-}\right)$ and phosphate $\left(\mathrm{PO}_{4}{ }^{3-}\right)$ ions, and it is this similarity that is the dominant source of their toxicity: arsenite and arsenate block ATP - ADP conversions by

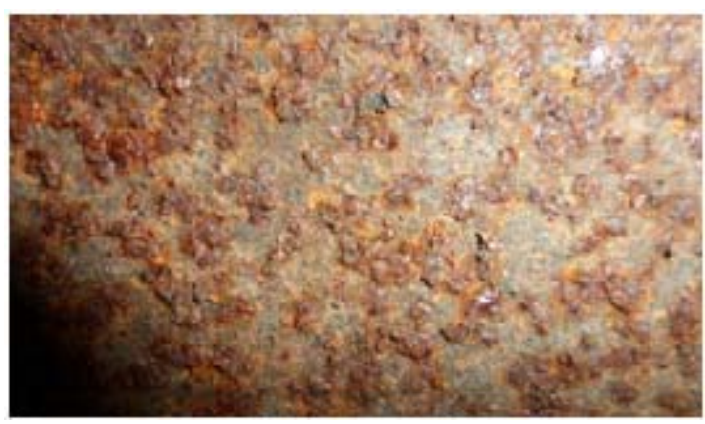

Fig. 5: Close view of Rusted iron sheet 
permanently replacing phosphate groups ${ }^{14}$. Although arsenic-contaminated ground water belongs to local scale pollution, this problem prevails all over the world. Traditional treatment technologies are not effective and magnetite nanoparticle seems to be a good alternative due to its

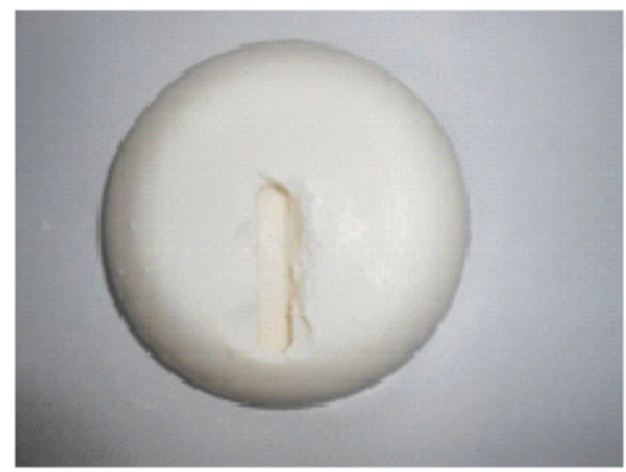

Fiq. 6: Canola oil soap
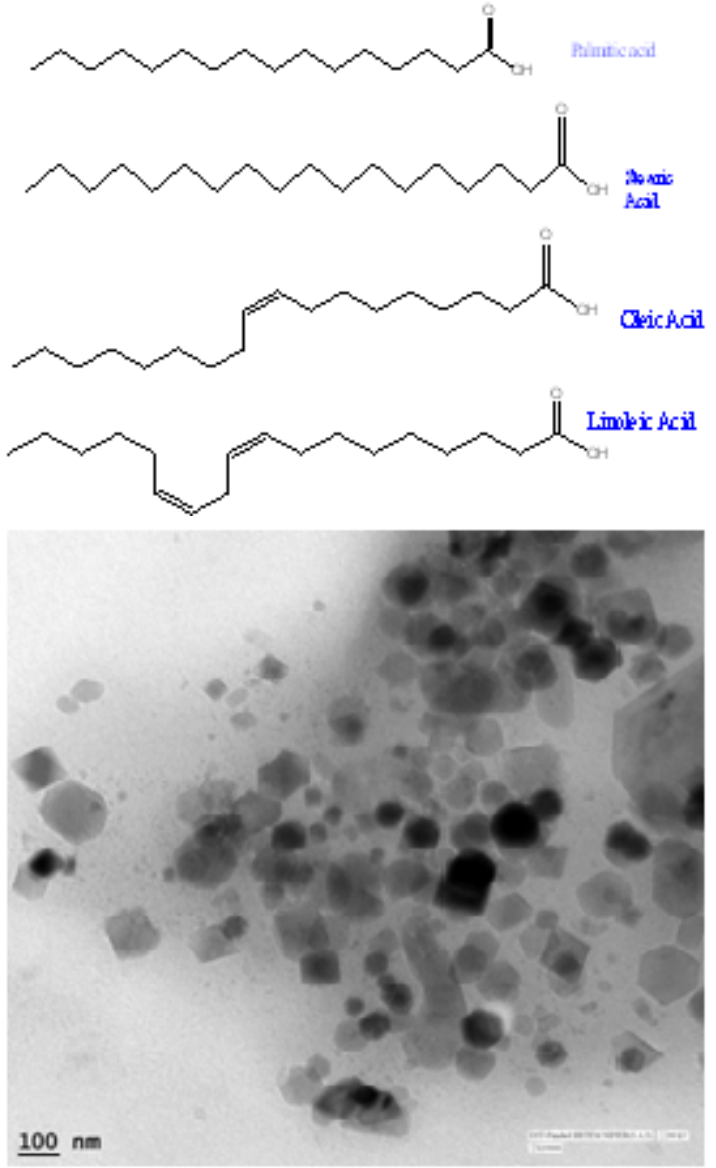

highly selective adsorption toward arsenic and feasibility on regeneration. This nanomaterial exhibited high $\mathrm{As}(\mathrm{V})$ adsorption capacity, up to $206.9 \mathrm{mg} \mathrm{g}-1$, which is the highest reported: ${ }^{[12]}$.

2. Nanomagnetites can be used as a green catalyst .

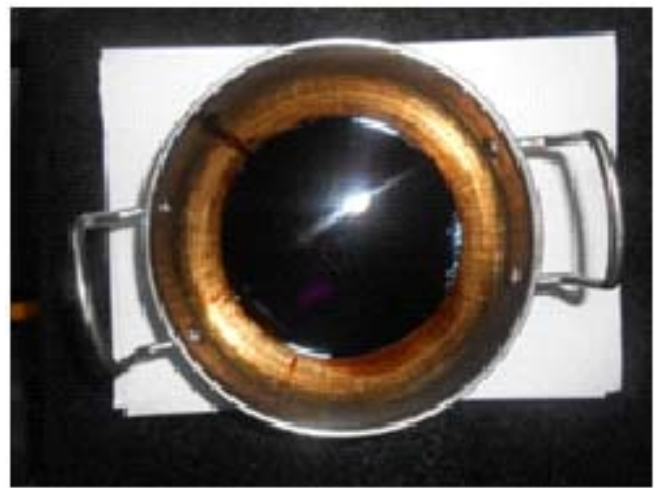

Fig. 7: Nanomagnetite slurry
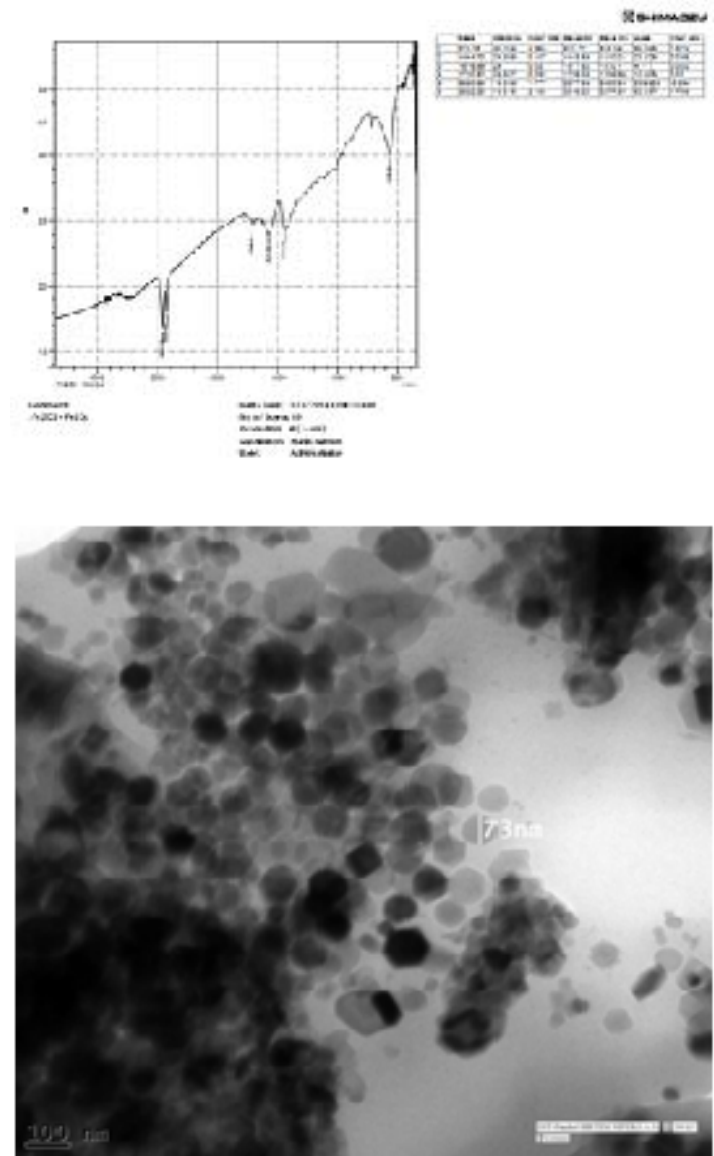

Instrument name: FEI Tecnai G2 F20, Analysed at 200KV. Courtesy :HRTEM Facility,NIPER, Mohali 
3. Nanomagnetite can be used as Encapsulation within polycaprolactone microspheres for bone replacement.

4. Nanomagnetite can be used for biomedical applications.

5. The two-dimensional arrays of nanomagnetite particles can be used for fundamental rock magnetic studies.

6. Nano-sized magnetite can be used for the wastewater treatment for ciprofloxin like biologically non-degradable antibiotics.

7. Nanomagnetite can be used in target drug delivery to enhance the curative effect and minimize the adverse effects of an anticancer drug.

8. Nanoparticles (SPIONs) with poly(d,Ilactide-co-glycolide) PLGA can be used to serve the dual work of MRI contrast improvement as well as direction of polymer particles to particular locations.

9. Magnetite and maghemite nanoparticles and their suspensions are widely used in different industrial applications like magnetic sealing, oscillation damping, position sensing or magnetic storage media $^{15}$. The ferrofluids contain iron oxide magnetite nanoparticles. Recently, ferrofluids have been used in conjunction with microcontact printing and capillary filling to fabricate patterned structures of magnetic materials on the micron scale. The ability to generate patterns of ultrafine magnetic particles has versatile technological applications, because of the information density on tapes, for instance, is inversely proportional to the size of the particles. Research has been done on finding the use of ferrofluids as magnetic inks for ink jet printing. Magnetic inks are presently used in printing USA paper currency, as can be demonstrated by the attraction of a genuine dollar bill to a strong magnet ${ }^{16}$.

\section{ACKNOWLEDGEMENTS}

The author like to give thanks to open source nanotechnology for providing additional platform for suggesting greener methods of nanomaterial synthesis(http://opensourcenano.net) and NIPER Mohali for HRTEM analysis.

\section{REFERENCES}

1. Roca, A. G., Morales, M. P., et al., Synthesis of monodispersed magnetite particles from different organometallic precursors. IEEE Transactions on Magnetics, 2006; 42(10): 3025-3029.

2. Sun, S. H., \& Zeng, H., Size-controlled synthesis of magnetite nanoparticies. Journal of the American Chemical Society, 2002; 124(28): 8204-8205.

3. Sun, S. H., Zeng, H., et al., Monodisperse $\mathrm{MFe}_{2} \mathrm{O}_{4}(\mathrm{M}=\mathrm{Fe}, \mathrm{Co}, \mathrm{Mn})$ nanoparticles. Journal of the American Chemical Society, 2004; 126(1): 273-279.

4. Yu, W. W., \& Falkner J. C., et al., Synthesis of monodisperse iron oxide nanocrystals by thermal decomposition of iron carboxylate salts. Chemical Communications, 2004; 20 : 2306-2307.

5. Jana, N. R., Chen, Y. F., et al., Size- and shapecontrolled magnetic ( $\mathrm{Cr}, \mathrm{Mn}, \mathrm{Fe}, \mathrm{Co}, \mathrm{Ni})$ oxide nanocrystals via a simple and general approach. Chemistry of Materials, 2004; 16(20): 3931-3935.

6. Park, J., An, K. J., et al., Ultra-large-scale syntheses of monodisperse nanocrystals. Nature Materials, 2004; 3(12): 891-895.

7. Gan, H. L., Man, Y. B. C., et al., Characterisation of vegetable oils by surface acoustic wave sensing electronic nose. Food Chemistry, 2005; 89(4): 507-518.

8. Misawa, T., Hashimot, K., et al., Mechanism of formation of iron-oxide and oxyhydroxides in aqueous-solutions at room-temperature. Corrosion Science, 1974; 14(2): 131-149.

9. Sapra, S., Rogach, A. L., et al., Phosphinefree synthesis of monodisperse CdSe nanocrystals in olive oil. Journal of Materials Chemistry, 2006; 16(33): 3391-3395.

10. Asokan, S., Krueger, K. M., et al., The use of heat transfer fluids in the synthesis of highquality CdSe quantum dots, core/shell quantum dots, and quantum rods. 
Nanotechnology, 2005; 16(10).

11. Hossain, M. A., Sengupta, M. K., et al., Ineffectiveness and poor reliability of arsenic removal plants in West Bengal, India. Environmental Science and Technology, 2005; 39(11), 4300-4306.

12. Yavuz T. C., Mayo T. J., Suchecki Carmen, Wang J., Ellsworth Z. A., D'Couto H., Quevedo E., Prakash A., Gonzalez L., Nguyen C., Kelty C., Colvin L. V., Pollution magnet: nanomagnetite for arsenic removal from drinking water, Environ Geochem Health 2009; 10, 10653-010-9293.

13. Gan, H. L., Man, Y. B. C., et al.,Characterisation of vegetable oils by surface acoustic wave sensing electronic nose. Food Chemistry,
2005; 89(4), 507-518.

14. Patel A. H., Jeehye Byun J., Yavuz T. C., Arsenic removal by magnetic nanocrystalline barium hexaferrite, Journal of Nanoparticle Research, 2012, 7/s11051-012-0881-x.

15. Keiichi M., Chuhyun C., Hisayuki S., Weihua J., Kiyoshi Y., Particle Size Distribution of Copper Nanosized Powders Prepared by Pulsed Wire Discharge, IEEJ Transactions on Fundamentals and Materials, 2005; 125(1), 39-44.

16. Adelman B. N., Beckman J. K., Campbell J. D., Ellis B. A., Lisensky C. J., Preparation and Properties of an Aqueous Ferrofluid, Journal of Chemical Education, 1999; 76(7), 943. 